\title{
VIDEO LECTURES AND ONLINE ACTIVITIES TO ENGAGE STUDENTS IN A FLIPPED CLASSROOM
}

\author{
Ana Paula Lopes ${ }^{1}$, Filomena Soares ${ }^{2}$ \\ ${ }^{1}$ Polytechnic Institute of Porto (IPP) / ISCAP - CICE / UIE (PORTUGAL) \\ ${ }^{2}$ Polytechnic Institute of Porto (IPP) / ESEIG (PORTUGAL)
}

\begin{abstract}
In recent years there have been several proposals for alternative pedagogical practices. Most of these proposals are based in the, so called, "active learning", in opposition to the common "passive learning", which is centered on transmission of information inside classrooms as well as recognized as teacher-centered procedure. In an active learning pedagogical structure, students have a more participative role in the overall learning/teaching process, being encouraged to face new learning challenges like, for instance, solving problems and developing projects, in an autonomous approach trying to make them, consequently, able to build their own knowledge. The flipped or "inverted" classroom is one of these active learning pedagogical methodologies that emphasizes a learnercentered instruction. According to this approach, the first contact that students have with the content on a particular curriculum subject is not transmitted by the lecturer in the classroom, this teaching strategy requires students to assess and analyze the specific subject before attending to class, therefore the informational component from the lecture is the homework, and class time is dedicated to exercises and assignments, always with support from the instructor, who acts as a facilitator, helping students when needed and offering supplementary explanation as required.
\end{abstract}

The main objective of this paper is to discuss and explore how the use of different types of instructional videos and online activities may be implemented in the flipped classroom procedure (as means of incorporating new content and teaching new competencies) and to describe students' perceptions of this approach within a course in a Higher Education Institution (HEI), presenting some positive and negative features of this pedagogical practice.

Keywords: Online Learning, Flipped Classroom, Higher Education, Video Lectures.

\section{INTRODUCTION}

Nowadays there is as a new model for organizing the educational process in Higher Educational Institutions (HEI) which has been attracting the attention of many researchers and educators all over the world. This model, called "Flipped Classroom", was developed by Jonathan Bergmann and Aaron Sams in 2000 [1], the pioneers of this trend, who at the time were chemistry teachers, at Woodland Park High School in Colorado, in an attempt to counter noticeable levels of student absenteeism, began to record their lessons and post them online, allowing students to access them remotely. Taking this step led them to question whether class time was in fact the best mean for delivering information to students at all; therefore, Bergmann and Sams became dedicated to prerecording their direct instruction for review outside the classroom, leaving class time for more meaningful learning activities and increased focus on more difficult concepts [2]. Hence the idea comes from reversing the traditional teaching paradigm where the main stages of the teaching and learning process such as classroom activities and homework are reversed. The flipped classroom is characterized by course structure: instructional content (e.g., pre-recorded video lectures) is assigned as homework before coming to class. In-class time is then spent working on problems, advancing concepts, and engaging in collaborative learning [3]. Therefore, according to this pedagogical approach, theoretical material can be delivered via reading materials, video lectures, online presentations, or any combination of different information transfer methods and studied by students individually. However, since available video lectures appear more appealing to the new generation of students, many instructors prefer using online videos instead of reading materials when preparing students out of-classroom for in-class active learning. So, most of the times students rely on video lectures recorded by their own lecturer or downloaded from Internet sites, while exercises, assignments and discussing the main issues with the lecturer are dedicated to classroom activities. With all structural changes instructors have been compelled to adapt quickly to this reality, building and developing a wide diversity of tools to grab student's attention and to motivate them to embrace the knowledge in their own learning process. One 
of the most engaging resources is the use of video lectures, as we already mentioned. Through them lecturers can deliver complex information and contents to students and, if used creatively, videos can become a powerful technological tool in the global and self-enrolment educational process [4]. Video differs from other teaching and learning technologies as allowing the benefit of using visual perception - "that powerful but neglected sense" [5] - in new ways. A moving image can help to see a process or realize how something works, moves, or performs, which is much more complex to transmit with static images or text.

The aim of this paper is to try to evaluate the efficiency of the flipped classroom technology implementation in the educational process at the Polytechnic of Porto (P. PORTO), specifically in Institute of Accounting and Administration of Porto (ISCAP). The purpose of this study is to give an overview of the studies dedicated to the description of the flipped classroom model, offer practical experience of the integration of the given technology into the process of the Mathematics teaching and understand students' views on flipped course. With this study we will attempt to find out how do ISCAP students prepare for a Financial Mathematics Class in a flipped process and what their opinions about this model are.

\section{LITERATURE REVIEW}

The Flipped Classroom phenomenon resulted from the recent efforts to improve student engagement. Also known as the "Inverted Classroom", it has been defined by several authors as a technique driven by technological innovations and the ability to share content online ([6], [7], [8], [9], [10]). Some of these authors compare the flipped classroom model to the traditional classroom setting and examine the potential benefits of this pedagogical technique and present the results of their studies comparing the impact of a flipped classroom to that of a traditional lecture. Some authors found that students in the flipped classroom scored significantly higher than students in the traditional classroom ([6], [8], [10]). The flipped classroom requires students to learn autonomously at home using online video lectures, among other learning resources, thus basic course content is communicated outside of class which allows students to contextualize the material and apply the concepts to various settings and actively participate in class for effective discussions ([11], [12], [13]). The first step in knowledge transfer process, in a flipped model can be readily accomplished by the individual student out of the classroom, and thereby leaves class time to focus on more in-depth and complex learning and skill sets [14]. The theoretical strength of this new pedagogy seems to be the combination of constructivist and behaviourist learning theories working together, in a continuous interaction [15].

One of the most common means of moving instruction outside the classroom in a flipped classroom format has been to require students to watch prerecorded video lectures or screencasts prior to attending class [16]. Video can present in a clear and striking manner descriptions to articulate tacit information and knowledge hard to describe through text [17]. Since the lecture is such a great portion of a class (even within the flipped classroom), it seems rational to observe whether prerecorded lectures have any impact, negative or positive, on learning. We can find in [18] a study where they explored 'the effect of the use of videos for assessing the enhancement of students' learning motivation". Today HEI are trying to get the best students and students search for the best learning experiences, so flipped classroom and, in this sense, the use of video lectures may be a particularly attractive tool to these students. HEI are faced with some important challenges, on one hand, make engaging video lectures with a low budget and with high-quality and, on the other hand, make video platforms more interactive for students, because this strategy according with [2], aligns well with the flipped classroom, where "we don't want to encourage passive viewership; we encourage interactivity." Even Harvard University, ever the academic benchmark, has succumbed to the allure of the flipped classroom. One Harvard physics professor not only employs the flipped model but has also developed an accompanying site entitled Learning Catalytics, which distributes free interactive software for other instructors to use that facilitates student discussion and application of concepts covered in lectures [19].

Recent studies report that the flipped classroom has a lot of benefits for students and teachers. For example, [20] reported that students are able to make progress at their own pace. Furthermore, doing homework in class provides a good opportunity for teachers to see students' difficulties and learning styles. This allows teachers to easily modify lessons according to students' needs within this model. Moreover, classroom time can be used more efficiently and creatively with a flipped classroom since students have the chance to familiarize themselves with the content before class sessions. In another recent study, two hundred science teachers implemented the flipped classroom model into their 
Science, Technology, Engineering and Mathematics (STEM) classrooms and found it had a big impact on student learning [21].

\section{METHOD}

As we mentioned before, a growing number of HEI have started to use the flipped classroom model in their courses and the video lecture is often seen as the key ingredient in the flipped approach, such lectures being either created by the instructor and posted online or selected from an online repository.

At P. PORTO/ISCAP, having some background analytics experience, granted by Moodle platforms and MatActiva Project ([22], [23], [24]), we have developed this flipped classroom. MatActiva Project mission is to offer to ISCAP students a free, online tool, which stores several instructional Math video lectures and hundreds of exercises (all of them with a suggestion for the solution). It is a personalized learning platform in which students can learn at their own pace through an entire Math subject. The sample consisted of 72 students enrolled in Financial Mathematics Course during the Winter 2015 semester in ISCAP. Student gender demographics consisted of 34 male and 38 female students. The course entailed six subjects/sections (Simple Interest, Compound Interest, Ordinary Annuities, Annuity Due, Loan Amortization and Bonds) throughout the semester, and students were provided with flipped classroom model opportunities in four sections out of these six. It means that, four sections were flipped and two sections were traditionally taught during the semester, and flipped and non-flipped (traditional) sections were compared. Accessing the MatActiva site www.matactiva.com (see Fig. 1) participants can access all the available sections in the Financial Mathematics Course.

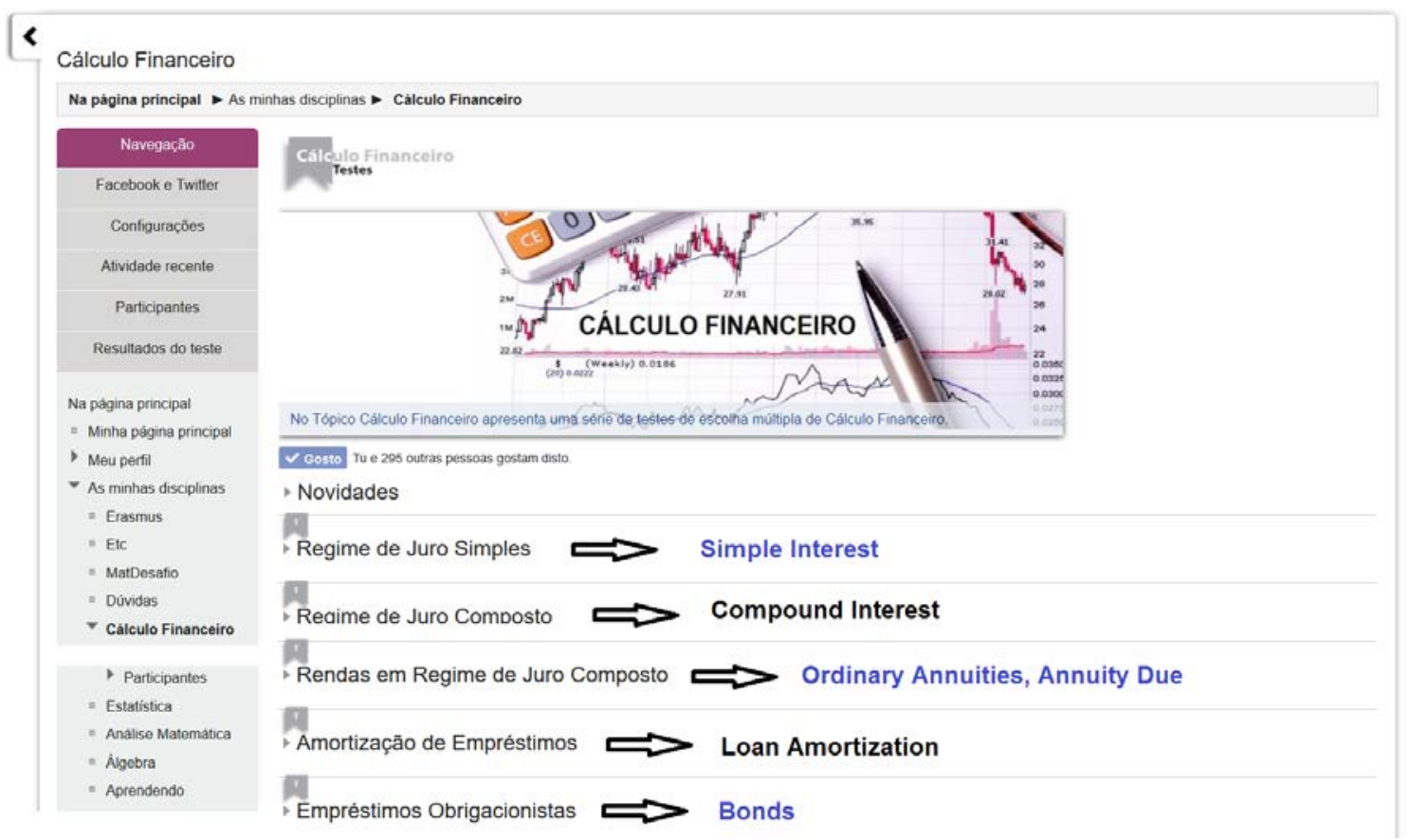

Figure 1 - Main page of Financial Mathematics (Cálculo Financeiro) Course in Moodle platform

A short survey was developed to find out how the flipped classroom model affected ISCAP Financial Mathematics students' training, understanding and their performance. This survey was given at the end of the semester to analyze participants' global thoughts about the use of the flipped model in their classes. More precisely, this survey was designed to try to discover in what way the flipped classroom (including short video lectures and interactive online exercises) helped these students. Although some studies reveal a smaller improvement in Mathematics than in other subjects [25] we feel that videolectures available in MatActiva Project have an important role in the work of prerequisites items, in which we feel (and know) the students have missed in their previous "educational life". The video materials available have been very successful and with a wide and strong utilization from our students. We also have used the Learning Analytics tools provided by Moodle platform for monitoring progress in real time. This platform offers to the teacher/administrator different analytical tools with a wide range of information reports on the numerous activities carried out by their students in a particular subject, 
which can be an important tool to improve, adapt and modify the subject in question [26]. Flipped instruction offers the opportunity to efficiently collect data on improved subject learning [14].

Financial Mathematics is one of the standard subjects for many HEI. In any regular Financial Mathematics Course, students are expected to be familiar with certain mathematical skills from high school or previous Mathematics courses. Nevertheless, generally speaking, there is a frequent lack in what the needed basic skills is concerned. So, in many different moments, Financial Mathematics lecturers use class sessions in order to review these background materials. The ideal situation would be students fill in this gap by doing the suggested research/homework before lectures, by reading related sections from a textbook in advance. Among new generation students, sad to say, this is not a common practice any longer [27]. For all the reasons presented, we decided to use the flipped classroom model in an attempt to improve students' achievement in Financial Mathematics course through changes in the way they prepare before attending class sessions. We prepared some video lectures (including some basic background material and a short introduction to the lecture) for students to watch before coming to class at different times during the semester and advised them to watch some particular educational videos from Khan Academy site. Short tutorial video lectures allow students to move at their own pace, rewind to review portions, and skip through sections they already understand, they might view multiple lectures of five to seven minutes each. It was not a surprise when we realize that many students found watching a 10 minutes video easier than reading a textbook about the same subject. Online quizzes and activities were combined to test what students have learned. Immediate quiz feedback and the ability to repeat lecture segments helped them to clarify some "grey" points in their minds. Inside classroom, students putted into practice what they have learned from the video lectures and many other resources they previously came across, collaborating and creating meaningful work, developing some tasks through several discussions with the instructors' supervision and guidance.

\section{RESULTS}

In our opinion, the flipped classroom model puts more of the responsibility for learning on the shoulders of students while giving them bigger motivation to experiment and experience new challenges.

We will use the results of continuous assessment and final exam to try to measure the success or failure of the flipped classroom model. If there were significant changes in the course results from previous years or the average course results are very different in relation to existing traditional classes then there might be evidence of impact. Table 1 shows the relationship of results of the 2014/15 (traditional classroom) group against those of the 2015/16 (flipped classroom) group.

Table 1 - Gauging the success of flipped classroom against average pass rate

\begin{tabular}{lcc}
\hline & $2014 / 2015$ & $2015 / 2016$ \\
\hline Flipped Classroom success rate & $71,4 \%$ & $90,5 \%$ \\
\hline Average success rate across all & $49,2 \%$ & $62,3 \%$ \\
Financial Mathematics courses & & \\
\hline
\end{tabular}

Source: Own elaboration

From Table 1, we can see that the success rate for the flipped classroom version increased by $20,1 \%$ from the starting point set in 2014/15. In order to more fully understand the groups' success rates, they need to be matched against the Financial Mathematics Course average for each year. While both iterations of flipped classroom clearly outperform the average success rate across the Financial Mathematics courses, the average success rate improved by $13,1 \%$ in $2015 / 16$. From this we can see that there was a slight increase in overall performance in the flipped classroom version in relation to successful students. We are very pleased about the flipped classroom model results, and we plan to use it again. The student success rate and the numeric grades in the flipped class supplanted, in a perfectly visible way, those obtained by students in the traditional class. 
Descriptive statistics revealed the diverse types of training students did before coming to face to face sessions that utilized flipped classroom. Table 2 summarizes the frequency of students' preparation preferences.

Table 2 - Students' preparation types in flipped classroom

\begin{tabular}{|c|c|c|c|c|c|c|c|c|c|c|}
\hline & $\begin{array}{l}\text { Watching } \\
\text { flipped } \\
\text { video }\end{array}$ & $\%$ & $\begin{array}{c}\text { Watching } \\
\text { other } \\
\text { videos }\end{array}$ & $\%$ & $\begin{array}{l}\text { Reading } \\
\text { the } \\
\text { textbook }\end{array}$ & $\%$ & $\begin{array}{l}\text { Reading } \\
\text { other } \\
\text { texts }\end{array}$ & $\%$ & $\begin{array}{c}\text { Doing } \\
\text { online } \\
\text { exercises }\end{array}$ & $\%$ \\
\hline $\mathbf{N}^{\circ}$ & 63 & 87,5 & 34 & 47,2 & 25 & 34,7 & 45 & 62,5 & 70 & 97,2 \\
\hline
\end{tabular}

Source: Own elaboration

From these statistics, it is clear that students preferred video lectures and doing online exercises for training more often than reading related preparations. The high number of students that are doing online exercises can, possibly, be explained due to the fact that a Question Pool was created from the ground up, grouped into categories and subcategories, on Financial Mathematics various topics. The combination of questions in each category is randomized and it generates a huge number of different tests that students can solve online, wherever they are and at a time that suits them. The tests allow multiple attempts, providing automatically quantitative results and each attempt is corrected immediately. For each wrong answer the feedback is presented with a suggested step by step solution, in order to help students to understand what went "wrong" with their answer, providing and promoting self-assessment and skill development.

A big number of participating students $(86,2 \%)$ stated that the video lectures helped them understand the concepts studied in Financial Mathematics (see Table 3). No students indicated any negative thoughts about flipped classroom video lectures.

Table 3 - Video lectures and students' preparation

\begin{tabular}{lcc}
$\begin{array}{l}\text { The video lectures helped me understand the concepts studied in } \\
\text { Financial Mathematics }\end{array}$ & Number & Percentage \\
\hline Strongly agree & 31 & $47,7 \%$ \\
\hline Agree & 25 & $38,5 \%$ \\
\hline Neither agree nor disagree & 9 & $13,8 \%$ \\
\hline Disagree & 0 & $0 \%$ \\
\hline Strongly disagree & 0 & $0 \%$ \\
\hline
\end{tabular}

Source: Own elaboration

It is amazing that in answering the question "Online exercises helped me gain solid knowledge and skills in Financial Mathematics", the majority of students $(95,4 \%)$ indicated that online exercises with solution step by step helped them perform better. Only $4,6 \%$ of the participants were neutral about the benefits of the online exercises in the flipped classroom, in terms of providing them better performance (see Table 4).

Table 4 - Online exercises and students' performance

\begin{tabular}{lcc}
$\begin{array}{l}\text { Online exercises helped me gain solid knowledge and skills in Financial } \\
\text { Mathematics }\end{array}$ & Number & Percentage \\
\hline Strongly agree & 41 & $63,1 \%$ \\
\hline Agree & 21 & $32,3 \%$ \\
\hline Neither agree nor disagree & 3 & $4,6 \%$ \\
\hline Disagree & 0 & $0 \%$ \\
\hline Strongly disagree & 0 & $0 \%$
\end{tabular}

Source: Own elaboration 
Before finishing this section, we present (Table 5) the global feedback results about flipped classroom preferences. In this same survey, to the question about the students preferences in relation to the flipped classroom, $66,2 \%$ prefer a flipped classroom. $23,1 \%$ of the participants were neutral about the preferences related with the flipped classroom and $10,8 \%$ of the participants prefer the traditional classroom.

Table 5 - Students' preferences

\begin{tabular}{lcc} 
I'd prefer a flipped classroom course over a traditional classroom course & Number & Percentage \\
\hline Strongly agree & 24 & $36,9 \%$ \\
\hline Agree & 19 & $29,2 \%$ \\
\hline Neither agree nor disagree & 15 & $23,1 \%$ \\
\hline Disagree & 7 & $10,8 \%$ \\
\hline Strongly disagree & 0 & $0 \%$
\end{tabular}

Source: Own elaboration

\section{CONCLUSION}

The flipped classroom is an innovative pedagogical approach that focuses on learner-centered instruction. The main purpose of this paper was to investigate how the incorporation of the flipped classroom model into a Financial Mathematics class, in Institute of Accounting and Administration of Porto, affected students' class training, learning, and achievement. In agreement with other studies on flipped classrooms ([13], [14], [21]), we set up that students in the flipped classroom preferred watching video lectures than reading textbooks about the issue they are studying. We also found that for student is very important the opportunity of doing online exercises and have access to their solutions (explained step by step). This study also shown that flipped classroom model caused an increase in student achievement in Financial Mathematics Course.

The integration of the flipped classroom into the educational process leads to an increase of students' motivation and interest for studying Financial Mathematics. Furthermore, it has a positive impact on students' determination and autonomy due to the fact that students take on responsibility for their own learning.

We asked students their opinion on their experiences in the flipped classroom and they wrote, "The video tutorials allowed for class time to be much more efficiently used, and the quizzes due before class provided a good incentive to stay on program"; "I liked the way that we watch video lectures at home and do the online exercises and then got to work on problems in class so that we had a chance to practice the material with professor there". Such positive evaluations, encourages us to continue with this project.

\section{REFERENCES}

[1] Bergmann, J., \& Sams, A. (2012). Flip Your Classroom: Reach Every Student in Every Class Every Day. Arlington: ISTE.

[2] Bergmann, J., \& Sams, A. (2014). Flipped learning: Maximizing face time. $T+D, 68$ (2), $28-31$.

[3] Findlay-Thompson, S., \& Mombourquette, P. (2014). Evaluation of a flipped classroom in an undergraduate business course. Business Education and Accreditation, 6, 63-71.

[4] Soares, F. B., Lopes, A. P. \& Vieira, I., (2015). Behind Video Lectures in A MOOC. Proceedings of 9th International Technology, Education and Development Conference - INTED2015, March 2015, Madrid, Spain, Pages: 435-440, ISBN: 978-84-606-5763-7, ISSN: 2340-1079.

[5] Moss, R. (1983). Video, the educational challenge. Croom Helm Ltd, London and Canberra.

[6] Albert, M., \& Beatty, B. J. (2014). Flipping the classroom applications to curriculum redesign for an introduction to management course: Impact on grades. Journal of Education for Business, 89(8), 419-424. http://dx.doi.org/10.1080/08832323.2014.929559. 
[7] Garver, M. S., \& Roberts, B. A. (2013). Flipping \& clicking yourway to higher-order learning. Marketing Education Review, 23(1), 17-22. http://dx.doi.org/10.2753/mer1052-8008230103.

[8] Rivera, E. (2015). Using the flipped classroom model in your library instruction course. The Reference Librarian, 56(1), 34-41.

[9] Kim, M. K., Kim, S. M., Khera, O., \& Getman, J. (2014). The experience of three flipped classrooms in an urban university: An exploration of design principles. The Internet and Higher Education, 22, 37-50. http://dx.doi.org/10.1016/j.iheduc.2014.04.003.

[10] Berrett, D. (2012). How 'flipping' the classroom can improve the traditional lecture. The Chronicle of Higher Education, 78(1), 36-41.

[11] Lemmer, C. A. (2013). View from the flip side: Using the inverted classroom to enhance the legal information literacy of the international LL. M. student. Law Library Journal, 105, 461-492.

[12] Schlairet, M. C., Green, R., \& Benton, M. J. (2014). The flipped classroom: Strategies for an undergraduate nursing course. Nurse Educator, 39(6), 321-325.

[13] Gilboy, M. B., Heinerichs, S., \& Pazzaglia, G. (2015). Enhancing student engagement using the flipped classroom. Journal of Nutrition Education and Behavior, 47(1), 109-114. http://dx.doi.org/10.1016/j.jneb.2014.08.008.

[14] Arnold-Garza, S. (2014). The Flipped Classroom Teaching Model and Its Use for Information Literacy Instruction. Communications in Information Literacy, 8(1), 8_22.

[15] Bishop, J.L., \& Verleger, M. (2013). The flipped classroom: A survey of the research. Paper presented at the 120th ASEE Annual Conference \& Exposition, June 23-25, Atlanta, GA.

[16] Abeysekera, L., \& Dawson, P. (2015). Motivation and cognitive load in the flipped classroom: definition, rationale and a call for research. Higher Education Research and Development, 34, $1-14$.

[17] Goodyear, P., Steeples, C. (1998). Creating shareable representations of practice, Advance Learning Technology Journal (ALT-J), Volume 6 Number 3 (16-23).

[18] Bravo, E.; Amante; B.; Simo, P.; Enache, M.; Fernandez, V. (2011). Video as a new teaching tool to increase student motivation. IEEE Global Engineering Education Conference (EDUCON), 638-642.

[19] Educause. (2012, February). 7 things you should know about flipped classrooms. Retrieved from http://net.educause.edu/ir/library/pdf/eli7081.pdf.

[20] Fulton, K. (2012). Upside down and inside out: Flip your classroom to improve student learning. Learning \& Leading with Technology, 39(8), 12-17.

[21] Herreid, C. F., \& Schiller, N. A. (2013). Case studies and the flipped classroom. Journal of College Science Teaching, 42(5), 62-66.

[22] Lopes, A., Babo, L., Azevedo, J. (2008). Teaching and Learning Mathematics Using Moodle. INTED2008 Abstracts Book ISBN: 978-84-612-0192-1 and INTED2008 CD Proceedings ISBN: 978-84-612-0190-7.

[23] Torres, C., Lopes, A., Babo, L., Azevedo, J. (2009). Developing Multiple-Choice Questions in Mathematics. ICERI 2009 - International Conference of Education, Research and Innovation, Proceedings CD ISBN: 978-84-613-2955-7, Abstracts CD ISBN: 978-84-613-2953-3.

[24] Babo, L., Azevedo, J., Torres, C., Lopes, A. (2010). New Challenges in Mathematics for the European Higher Education. In proceedings of ICERI 2010, International Conference of Education, Research and Innovation, Proceedings CD ISBN: 978-84-614-2439-9, Abstracts CD ISBN: 978-84-614-2438-2.

[25] Barbier, Joel; Cevenini, Pete and Crawford, Alain (2012), Video Solves Key Challenges in Higher Education - Video Solutions Help Universities Improve Instruction and Expand Reach Without Straining Tuitions or Budgets, Cisco IBSG (C) 2012. Retrieved from http://www.cisco.com/web/about/ac79/docs/re/Video-in-Higher-Education.pdf 
[26] Lopes, A. P., Soares, F., (2016). "The Development and Implementation of Math Projects in a Hei - Expectations, Objectives, Experiences and Analysis". In 10th International Technology, Education and Development Conference - INTED2016 Proceedings, $7^{\text {th }}-9^{\text {th }}$ March 2016, Valencia, Spain, Pages: 6522-6530, ISBN: 978-84-608-5617-7, ISSN: 2340-1079, doi: 10.21125/inted.2016.0540

[27] Hoeft, M. E. (2012). Why university students don't read: What professors can do to increase compliance. International Journal for the Scholarship of Teaching and Learning, 6(2), 12. 